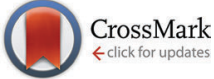

Cite this: Chem. Commun., 2016, 52,2609

Received 19th November 2015 Accepted 5th January 2016

DOI: $10.1039 / \mathrm{c} 5 \mathrm{cc} 09581 \mathrm{f}$

www.rsc.org/chemcomm

\section{Asymmetric synthesis of cyclopentanes bearing four contiguous stereocenters via an NHC-catalyzed Michael/Michael/esterification domino reaction $\dagger$}

\author{
Tao Shu, ${ }^{a}$ Qijian $\mathrm{Ni}^{a}{ }^{a}$ Xiaoxiao Song, ${ }^{a}$ Kun Zhao, ${ }^{a}$ Tianyu Wu, ${ }^{a}$ Rakesh Puttreddy, \\ Kari Rissanen ${ }^{b}$ and Dieter Enders*a
}

\begin{abstract}
An NHC-catalyzed Michael/Michael/esterification domino reaction via homoenolate/enolate intermediates for the asymmetric synthesis of tetrasubstituted cyclopentanes bearing four contiguous stereocenters is described. A variety of $\alpha, \beta$-unsaturated aldehydes and 2-nitroallylic acetates react well with good domino yields and high stereoselectivities.
\end{abstract}

Cyclopentane motifs are privileged scaffolds present as characteristic structural features in a large number of bioactive natural products and pharmaceuticals such as for instance aristeromycin, ${ }^{1}$ travoprost, $^{2}$ pactamycin ${ }^{3}$ and peramivir ${ }^{4}$ (Fig. 1). However, to develop direct and efficient catalytic methods for the stereocontrolled construction of multi-substituted cyclopentanes is still challenging for organic chemists. ${ }^{5}$

Nitroalkenes are among the most useful Michael acceptors due to their versatile reactivity and their inherent capacity to undergo further synthetic transformations of the nitro function into other functional groups. ${ }^{6}$ NHC-catalyzed cascade reactions have emerged as a powerful tool to construct $\mathrm{C}-\mathrm{C}$ bonds in organic synthesis ${ }^{7}$ and NHC-catalyzed reactions with nitroalkenes gained quite some interest in recent years. ${ }^{8}$ The first NHCcatalyzed homoenolate reaction of enals with nitroalkenes to afford anti $\delta$-nitroesters was reported by Nair and co-workers. ${ }^{9 a}$ Later the groups of Liu and Rovis reported complementary asymmetric versions of this reaction affording anti and syn $\delta$-nitroesters, respectively. ${ }^{9 b-d}$ Very recently, Wang and co-workers have also developed an NHC-catalyzed reaction of enals with nitroalkenes to prepare enantioenriched dihydrocoumarins. ${ }^{8 i}$

Nitroallylic acetates served as versatile dielectrophiles to assemble relatively complex molecules in a domino fashion. ${ }^{10}$

\footnotetext{
${ }^{a}$ Institute of Organic Chemistry, RWTH Aachen University, Landoltweg 1, 52074, Aachen, Germany.E-mail: enders@rwth-aachen.de

${ }^{b}$ Department of Chemistry, University of Jyväskylä, 40014 Jyväskylä, Finland $\dagger$ Electronic supplementary information (ESI) available: Experimental procedures and characterization date (NMR, IR, MS, HPLC). CCDC 1437686. For ESI and crystallographic data in CIF or other electronic format see DOI: 10.1039/c5cc09581f
}

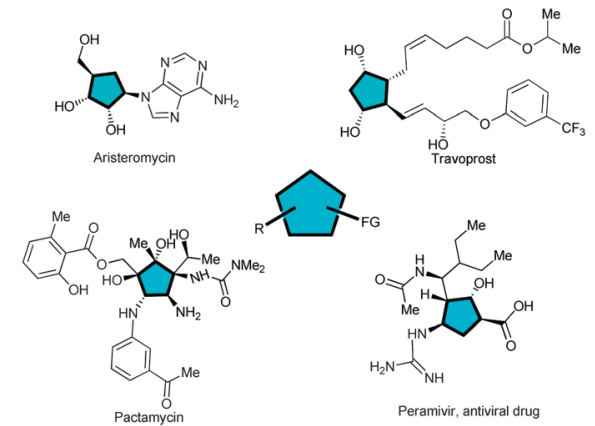

Fig. 1 Representative natural products and pharmaceuticals bearing a cyclopentane core.

Seebach and co-workers developed a [3+3] carbocyclization reaction of 2-nitroallylic acetates and enamines to form bicyclic skeletons with multiple stereocenters using the chiral auxiliary concept under stoichiometric conditions. ${ }^{10 a}$ An organocatalytic domino reaction of 2-nitroallylic acetates had not been reported until 2009. Tang and Li et al. developed a pyrrolidine-thiourea catalyzed tandem reaction of 2-nitroallylic acetates and cyclic ketones to construct bicyclic [3.3.1] skeletons with four or five stereocenters in a single operation. ${ }^{10 b}$ However, to the best of our knowledge, an NHC-catalyzed cascade reaction employing 2-nitroallylic acetates has not been reported yet. Herein, we describe such an NHC organocatalyzed [3+2]-cycloaddition reaction of enals with (E)-2-nitroallylic acetates to afford enantioenriched tetrasubstituted cyclopentanes with four contiguous stereocenters featuring a nitro and an ester group, which can be used for further transformations.

Initially we investigated the reaction of cinnamaldehyde (1a) and (E)-2-nitroallylic acetate $\mathbf{2 a}$ as model substrates catalyzed by the NHC catalysts derived from the pre-catalysts A-F in THF/ EtOH using one equivalent of NaOAc as a base. The aminoindanolbased triazolium pre-catalyst $\mathbf{B}$ provided the desired cyclopentane product 3a in 30\% yield and 78:22 e.r., albeit with a low diastereoselectivity (d.r. $3: 1$ ) (Table 1). 
Table 1 Optimization of the reaction conditions ${ }^{a}$

\begin{tabular}{llllllll}
\hline & & & & \\
\end{tabular}

${ }^{a}$ Reaction conditions: 1a $(0.3 \mathrm{mmol}), 2 \mathrm{a}(0.2 \mathrm{mmol})$, NHC catalyst (10 mol\%), base (1.0 equiv.), $24 \mathrm{~h}$ at rt. ${ }^{b}$ Yield of isolated compound $3 \mathrm{a}$. ${ }^{c}$ d.r. determined by ${ }^{1} \mathrm{H}$ NMR. ${ }^{d}$ The e.r. values were determined by HPLC on a chiral stationary phase. ${ }^{e}$ The reaction was carried out at $-5{ }^{\circ} \mathrm{C}$, $48 \mathrm{~h} .{ }^{f}$ The reaction was carried out at $-15{ }^{\circ} \mathrm{C}, 96 \mathrm{~h} .{ }^{g}$ The reaction was carried out at $-10^{\circ} \mathrm{C}, 60 \mathrm{~h}$.

After the screening of the solvents, $\mathrm{CHCl}_{3}$ turned out to be the best solvent, affording 3a in a good domino yield of $45 \%$, a d.r. of $3.6: 1$ and an e.r. of $85: 15$ (entry 7). The reaction proceeded well with different bases (entries 13-20). Using strong organic bases such as DBU or DMAP resulted in complex mixtures without any starting material remained and no desired product could be detected. We also screened some Lewis acid additives such as $\mathrm{Mg}(\mathrm{OtBu})_{2}, \mathrm{Ti}(\mathrm{OiPr})_{4}$ and $\mathrm{Sc}(\mathrm{OTf})_{3}$ and also $\mathrm{MgSO}_{4}$ as well as $4 \AA$ molecular sieves, but no better result was obtained. Lowering the reaction temperature improved the d.r. and e.r., but the reaction time was extended. The reaction proceeded well at $-5{ }^{\circ} \mathrm{C}(49 \%$ yield, $7.8: 1$ d.r, $91: 9$ e.r) in $48 \mathrm{~h},-15{ }^{\circ} \mathrm{C}(40 \%$ yield, $>20: 1$ d.r., $93: 7$ e.r.) in $96 \mathrm{~h}$ with starting material left and $-10{ }^{\circ} \mathrm{C}(52 \%$ yield, $16: 1$ d.r., $93: 7$ e.r. $)$ in $60 \mathrm{~h}$. Lowering the loading of the base gave inferior results. Finally, we chose pre-catalyst $\mathbf{B}, \mathrm{CHCl}_{3}$ : EtOH $(10: 1), \mathrm{K}_{3} \mathrm{PO}_{4}$ $(100 \mathrm{~mol} \%)$ at $-10{ }^{\circ} \mathrm{C}$ as the optimized condition for our reaction (entry 22).

With the optimized conditions in hand, we next evaluated the substrate scope with respect to the enals and 2-nitroallylic
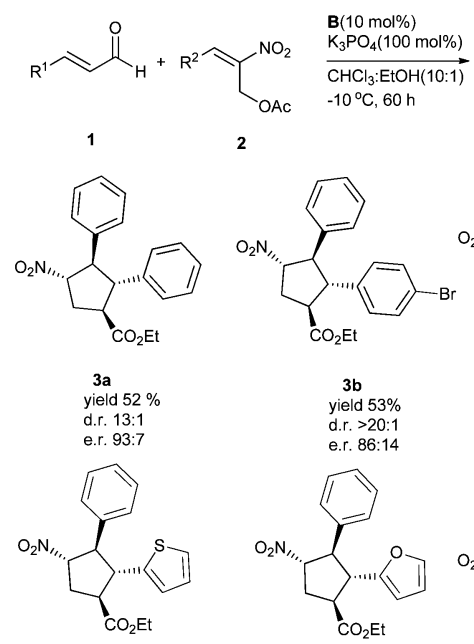<smiles>[R]C1C([N+](=O)[O-])C[C@@H](O[CH])[C@H]1[R]</smiles>
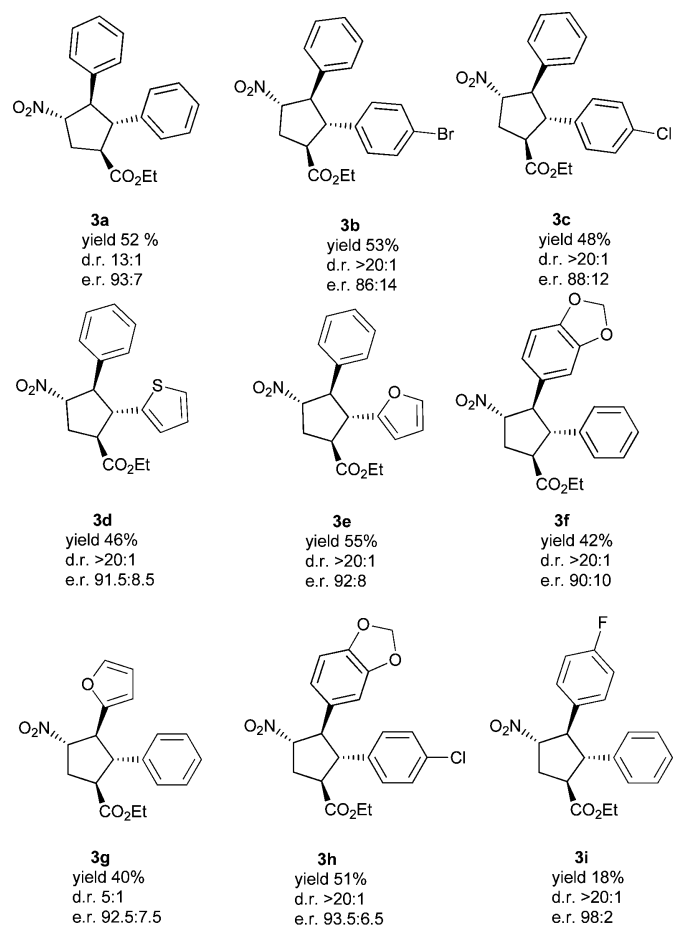

$$
\begin{aligned}
& 3 f \\
& \text { yield } 42 \% \\
& \text { d.r. }>20: 1
\end{aligned}
$$

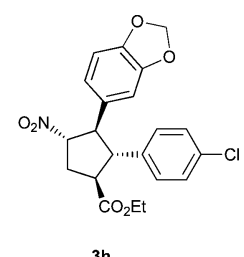

e.r. $90: 10$
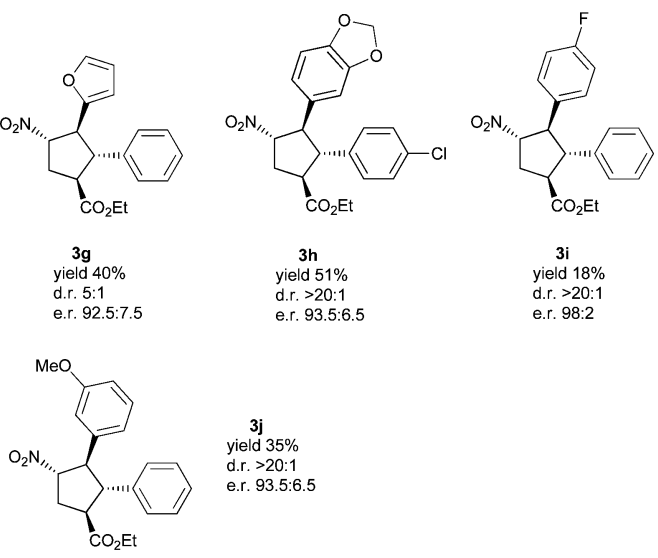

d.r. $>20: 1$

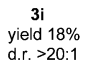

yield $18 \%$

e.r. $98: 2$

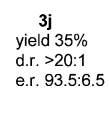

Scheme 1 Substrate scope. All reactions were performed on a $0.5 \mathrm{mmol}$ scale. The yields of the isolated products are after column chromatography. The diastereomeric ratios were determined by ${ }^{1} \mathrm{H}$ NMR spectroscopy and the e.r. values by HPLC on a chiral stationary phase.

acetates. With different substituted cinnamaldehydes, heterocyclic enals or (E)-2-nitroallylic acetates, the reaction proceeded well, affording the desired products in good domino yields (18-55\%) and enantiomeric ratios (86:14-98:2) (Scheme 1).

The absolute configuration was unambiguously determined by X-ray crystal structure analysis of compound $3 \mathbf{h}$ and all other cyclopentane products were assigned by analogy (Fig. 2).

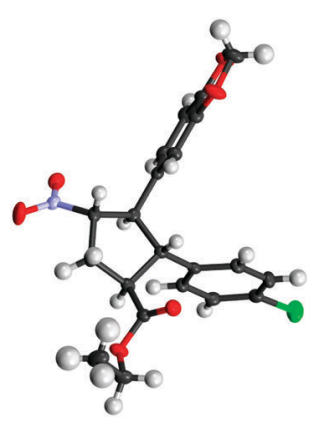

Fig. 2 Absolute configuration of $\mathbf{3 h}$ determined by $\mathrm{X}$-ray structural analysis. ${ }^{11}$ 


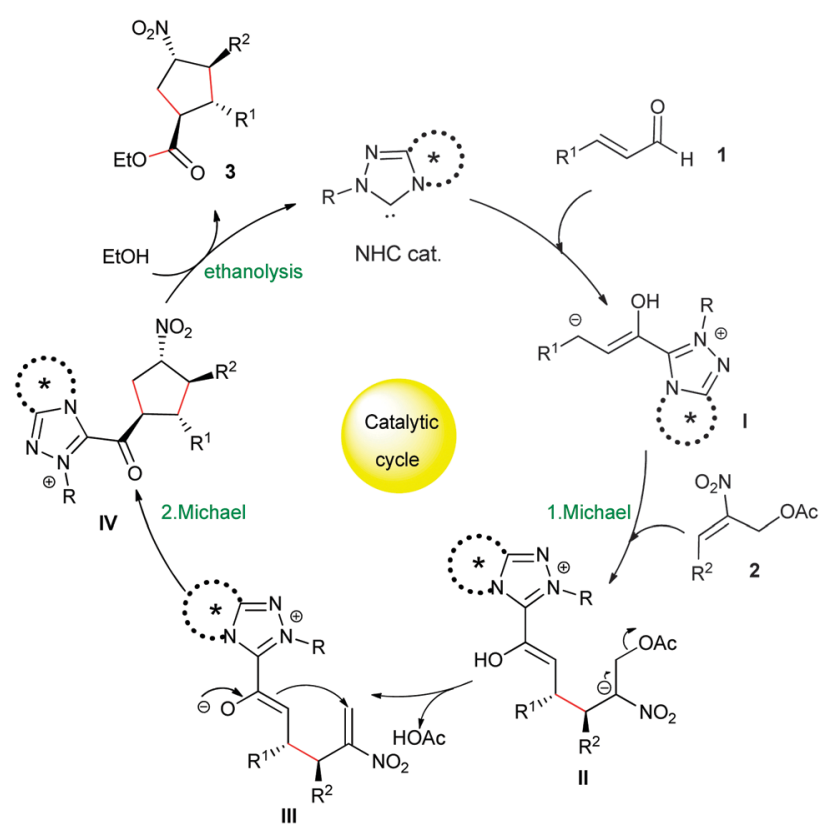

Scheme 2 Proposed catalytic cycle.

A plausible mechanism for the NHC-catalyzed [3+2] Michael/ Michael/esterification cascade is shown in Scheme 2. The reaction proceeds via an extended Breslow intermediate, which as a homoenolate I undergoes a first Michael addition to the nitroallylic acetates $\mathbf{2}$, followed by the elimination of the acetyl group from the adduct II to generate the second Michael acceptor intermediate III for the intramolecular Michael addition. The resulting acylazolium intermediate IV undergoes an ethanolysis with external ethanol to afford the cyclopentane esters 3 and returns the NHC catalyst for further cycles.

In conclusion, we have developed a concise protocol for the NHC-catalyzed direct construction of functionalized cyclopentanes bearing four contiguous stereocenters in one single operation with good domino yields and stereoselectivities. A range of functional groups and substituents are tolerated by variation of the enal and nitroallylic acetate substrates. In the novel one-pot protocol two $\mathrm{C}-\mathrm{C}$ bonds via Michael addition and one $\mathrm{C}-\mathrm{O}$ bond through a terminating ethanolysis step are formed.

We thank the European Research Council (ERC Advanced Grant 320493 "DOMINOCAT") for financial support and the BASF SE for the donation of chemicals.

\section{Notes and references}

1 (a) H. J. Bestmann and D. Roth, Synlett, 1990, 751; (b) S. J. Boyer and J. W. Leahy, J. Org. Chem., 1997, 62, 3976.

2 J. T. Whitson, Expert Opin. Pharmacother., 2002, 3, 965.

3 (a) S. Hanessian, R. R. Vakiti, S. Dorich, S. Banerjee, F. Lecomte, J. R. DelValle, J. Zhang and B. Deschênes-Simard, Angew. Chem., Int. Ed., 2011, 50, 3497; (b) J. T. Malinowski, R. J. Sharpe and J. S. Johnson, Science, 2013, 340, 180.

4 (a) Y. S. Babu, P. Chand, S. Bantia, P. Kotian, A. Dehghani, Y. ElKattan, T.-H. Lin, T. L. Hutchison, A. J. Elliott, C. D. Parker, S. L. Ananth, L. L. Horn, G. W. Laver and J. A. Montgomery, J. Med.
Chem., 2000, 43, 3482; (b) P. Chand, P. L. Kotian, A. Dehghani, Y. ElKattan, T.-H. Lin, T. L. Hutchison, Y. S. Babu, S. Bantia, A. J. Elliott and J. A. Montgomery, J. Med. Chem., 2001, 44, 4379; (c) P. Chand, Y. S. Babu, S. Bantia, S. Rowland, A. Dehghani, P. L. Kotian, T. L. Hutchison, S. Ali, W. Brouillette, Y. El-Kattan and T.-H. Lin, J. Med. Chem., 2004, 47, 1919.

5 (a) T. Hudlicky and J. D. Price, Chem. Rev., 1989, 89, 1467; (b) M. Lautens, W. Klute and W. Tam, Chem. Rev., 1996, 96, 49; (c) B. Heasley, Eur. J. Org. Chem., 2009, 1477; (d) V. Nair, B. P. Babu, S. Vellalath, V. Varghese, A. E. Raveendran and E. Suresh, Org. Lett., 2009, 11, 2507; (e) P.-C. Chiang, M. Rommel and J. W. Bode, J. Am. Chem. Soc., 2009, 131, 8714; $(f)$ J. Kaeobamrung and J. W. Bode, Org. Lett., 2009, 11, 677; $(g)$ D. T. Cohen, B. Cardinal-David and K. A. Scheidt, Angew. Chem., Int. Ed., 2011, 50, 1678; (h) G. Liu, M. E. Shirley, K. N. Van, R. L. McFarlin and D. Romo, Nat. Chem., 2013, 5, 1049; (i) B. T. Parr and H. M. L. Davies, Nat. Commun., 2014, 5, 1; $(j)$ L.-H. Zou, A. R. Philipps, G. Raabe and D. Enders, Chem. Eur. J., 2015, 21, 1004; (k) S. Mukherjee, S. Mondal, A. Patra, R. G. Gonnadeb and A. T. Biju, Chem. Commun., 2015, 51, 9559.

6 For a review, see: O. M. Berner, L. Tedeschi and D. Enders, Eur. J. Org. Chem., 2002, 1877.

7 For reviews on NHC-catalyzed domino reactions, see: (a) A. Grossmann and D. Enders, Angew. Chem., Int. Ed., 2012, 51, 314; (b) P. Chauhan and D. Enders, Angew. Chem., Int. Ed., 2014, 53, 1485; (c) M. N. Hopkinson, C. Richter, M. Schedler and F. Glorius, Nature, 2014, 510, 485; For pioneering work on homoenolate intermediates, see: $(d)$ C. Burstein and F. Glorius, Angew. Chem., Int. Ed., 2004, 43, 6205; (e) S. S. Sohn, E. L. Rosen and J. W. Bode, J. Am. Chem. Soc., 2004, 126, 14370; For reviews on homoenolate intermediates, see: $(f)$ V. Nair, S. Vellalath and B. P. Babu, Chem. Soc. Rev., 2008, 37, 2691; (g) V. Nair, R. S. Menon, A. T. Biju, C. R. Sinu, R. R. Paul, A. Jose and V. Sreekumar, Chem. Soc. Rev., 2011, 40, 5336; (h) D. T. Cohen and K. A. Scheidt, Chem. Sci., 2012, 3, 53; (i) P.-C. Chiang and J. W. Bode, TCI MAIL, 2011, 149, 2; $(j)$ R. S. Menon, A. T. Biju and V. Nair, Chem. Soc. Rev., 2015, 44, 5040; (k) D. M. Flanigan, F. Romanov-Michailidis, N. A. White and T. Rovis, Chem. Rev., 2015, 115, 9307.

8 For NHC-catalyzed reactions with nitroalkenes, see: (a) A. E. Mattson, A. M. Zuhl, T. E. Reynolds and K. A. Scheidt, J. Am. Chem. Soc., 2006, 128, 4932; (b) D. A. DiRocco, K. M. Oberg, D. M. Dalton and T. Rovis, J. Am. Chem. Soc., 2009, 131, 10872; (c) D. A. DiRocco and T. Rovis, J. Am. Chem. Soc., 2011, 133, 10402; (d) D. A. DiRocco, E. L. Noey, K. N. Houk and T. Rovis, Angew. Chem., Int. Ed., 2012, 51, 2391; (e) Q. Ni, H. Zhang, A. Grossmann, C. C. J. Loh, C. Merkens and D. Enders, Angew. Chem., Int. Ed., 2013, 52, 13562; $(f)$ X.-Y. Chen, L.-H. Sun and S. Ye, Chem. - Eur. J., 2013, 19, 4441; $(g)$ Y. Du, Y. Wang, X. Li, Y. Shao, G. Li, R. D. Webster and Y. R. Chi, Org. Lett., 2014, 16, 5678; (h) Q. Zhang, H.-Z. Yu and Y. Fu, Org. Chem. Front., 2014, 1, 614; (i) Z. Wu, X. Wang, F. Li, J. Wu and J. Wang, Org. Lett., $2015,17,3588$.

9 For homoenolate additions to nitroalkenes, see: $(a)$ V. Nair, C. R. Sinu, B. P. Babu, V. Varghese, A. Jose and E. Suresh, Org. Lett., 2009, 11, 5570; (b) B. Maji, L. Ji, S. Wang, S. Vedachalam, R. Ganguly and X.-W. Liu, Angew. Chem., Int. Ed., 2012, 51, 8276; (c) N. A. White, D. A. DiRocco and T. Rovis, J. Am. Chem. Soc., 2013, 135, 8504; (d) N. A. White, K. E. Ozboya, D. M. Flanigan and T. Rovis, Asian J. Org. Chem., 2014, 3, 442.

10 For cascade reactions of nitroallylic acetates, see: $(a)$ D. Seebach, M. Missbach, G. Calderari and M. Eberle, J. Am. Chem. Soc., 1990, 112, 7625; (b) C.-L. Cao, Y.-Y. Zhou, J. Zhou, X.-L. Sun, Y. Tang, Y.-X. Li, G.-Y. Li and J. Sun, Chem. - Eur. J., 2009, 15, 11384; (c) D. K. Nair, S. M. Mobin and I. N. N. Namboothiri, Tetrahedron Lett., 2012, 53, 3349; (d) D. K. Nair, S. M. Mobin and I. N. N. Namboothiri, Org. Lett., 2012, 14, 4580; (e) L. F. Yeh, S. Anwar and K. Chen, Tetrahedron, 2012, 68, 7317; $(f)$ W.-Y. Huang, Y.-C. Chen and K. Chen, Chem. - Asian J., 2012, 7, 688; $(g)$ T. Kumar, S. M. Mobin and I. N. N. Namboothiri, Tetrahedron, 2013, 69, 4964; (h) S. Anwar, W.-Y. Huang, C.-H. Chen, Y.-S. Cheng and K. Chen, Chem. - Eur. J., 2013, 19, 4344; (i) D. K. Nair, R. F. S. Menna-Barreto, E. N. da Silva Junior, S. M. Mobin and I. N. N. Namboothiri, Chem. Commun., 2014, 50, 6973; $(j)$ T. Zhang, N. Shao, H. Zhu, T. Chen, Q. Zheng and H. Zou, Tetrahedron, 2014, 70,7454 .

11 CCDC 1437686. 